\title{
Investigation on Tool Life and Surface Integrity when Drilling Ti-6Al-4V and Ti-5Al-4V-Mo/Fe
}

\author{
Erween Abd. RAHIM* ${ }^{* *}$ and Safian SHARIF***
}

\begin{abstract}
Machinability study on the drilling of two alpha beta titanium alloy series, Ti-6Al-4V and Ti-5Al-4V-0.6Mo-0.4Fe were conducted using an uncoated carbide drill. The effect of cutting speed on tool life, tool failure mode, cutting force and surface integrity of the drilled surface were discussed. Results showed that Ti-6Al-4V exhibited a more superior machinability property when compared to the Ti-5Al-4V-Mo/Fe alloy system. The tool wear progression when drilling Ti-6Al-4V was lower than that of Ti-5Al-4V-Mo/Fe. The tool experienced similar failure mechanisms which were non uniform wear and chipping when drilling both alloys. At high cutting speed and after prolonged machining, excessive plastic deformation was observed on the subsurface layer of the drilled surface which resulted in increase in the hardness value.
\end{abstract}

Key Words: Titanium Alloys, Drilling, Tool Life, Surface Integrity

\section{Introduction}

For the past decades, titanium alloys are being used in various applications such as in modern aerospace structure, marine, automotive, sport equipments and chemical apparatus. The wide application of these alloys is mainly due to their strength-to-weight ratio that can be maintained at elevated temperatures, excellent corrosion and fracture resistance and low modulus of elasticity ${ }^{(1)-(4)}$. However, machining of titanium and its alloys can be considered very difficult due to its highly chemical reactivity and tendency to weld to the cutting tool, which resulted in edge chipping and rapid tool failure ${ }^{(4)}$. The advancement in the development of cutting tools for the past few decades showed little improvement in the machinability of titanium alloys. Previous studies ${ }^{(5),(6)}$ have shown that straight tungsten carbide (WC/Co) tools still remains the recommended tool when machining titanium alloys. Until today, the alpha beta titanium alloy, Ti-6Al-4V is known to be the workhorse for aerospace and non-aerospace applications. Recently a new alloy, Ti-5Al-4V-0.6-Mo-0.4Fe (Ti-5Al-4V-Mo/Fe) or so-called a low-cost titanium al-

* Received 17th October, 2005 (No. 05-5110)

** Faculty of Mechanical and Manufacturing Engineering, University of College Technology Tun Hussein Onn, 86400 Parit Raja, Batu Pahat, Johor 86400, Malaysia. E-mail: erween@kuittho.edu.my

*** Faculty of Mechanical Engineering, Universiti Teknologi Malaysia, 81310 Skudai, Johor 81310, Malaysia. E-mail: safian@fkm.utm.my loy has been developed to minimize the production cost through the utilization of existing titanium alloy scrap and low cost alloying additions, which was also designed to be suitable for low cost melting and processing methods.

According to Tonshoff et al. ${ }^{(7)}$, drilling is one of the most important metal cutting operations, comprising approximately $30 \%$ of all metal cutting operations. Despite the extensive research on drilling of Ti-6Al-4V over the past 10 years $^{(8)-(11)}$, reports on the drilling of Ti-5Al$4 \mathrm{~V}-\mathrm{Mo} / \mathrm{Fe}$ are still limited, perhaps due to the limited availability of the material commercially. Previous study by Kosaka et al. ${ }^{(12)}$ indicated that Ti-5Al-4V-Mo/Fe alloy possessed superior machinability in both drilling and turning tests when compared to Ti-6Al-4V.

The aim of this study is to investigate the machinability of both Ti-6Al-4V and Ti-5Al-4V-Mo/Fe alloys when drilling using a K-grade WC-Co carbide drill. The effect of cutting speeds on tool life, tool wear, thrust force and surface integrity of the drill surface are evaluated.

\section{Material and Methods}

The workpiece materials used in the experiments are Ti-6Al-4V and Ti-5Al-4V-Mo/Fe. The nominal chemical composition and the microstructure for both workpiece materials are given in Table 1 and Fig. 1 respectively. The average hardness of Ti-6Al-4V and Ti-5Al-4V-Mo/Fe were $330 \mathrm{Hv}$ and $280 \mathrm{Hv}$ respectively.

Drilling tests were conducted under the conditions shown in Table 2. All the cutting tools used were manufactured from K30 grade, WC-Co carbide as shown in Fig. 2. 


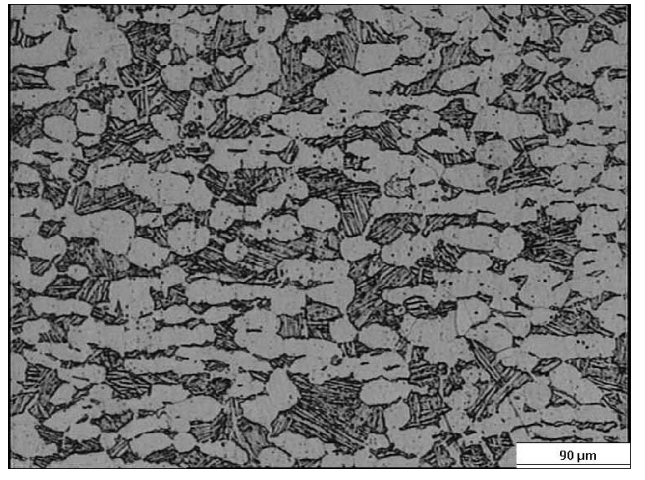

(a)

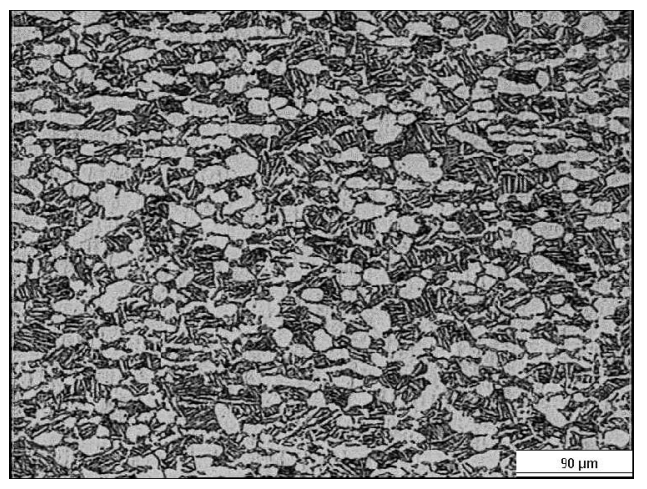

(b)

Fig. 1 Microstructure of (a) Ti-6Al-4V and (b) Ti-5Al-4V-Mo/Fe
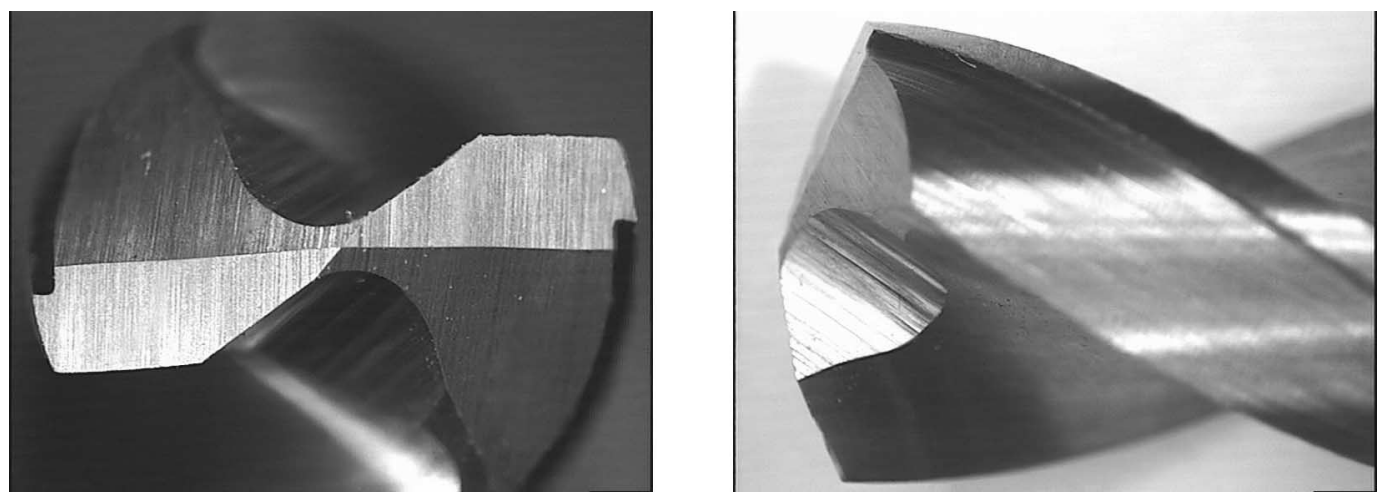

Fig. 2 Drill geometry

Table 1 Chemical composition (wt. \%)

\begin{tabular}{cccccccc}
\hline Alloy & $\mathrm{Al}$ & $\mathrm{V}$ & $\mathrm{Fe}$ & $\mathrm{C}$ & $\mathrm{Mo}$ & $\mathrm{Si}$ & $\mathrm{Ti}$ \\
\hline Ti-6Al-4V & 6.37 & 3.89 & 0.16 & 0.002 & $\sim 0.01$ & 0.01 & Bal. \\
\hline Ti-5Al-4V-Mo/Fe & 4.9 & 3.7 & 0.34 & 0.01 & 0.53 & 0.03 & Bal. \\
\hline
\end{tabular}

Table 2 Drilling test conditions

\begin{tabular}{l|l}
\hline Tool grade & WC-Co $(\mathrm{K} 30)$ \\
Tool geometries & diameter $: 6 \mathrm{~mm}$, helix angle: \\
& $25^{\circ}$, point angle: $120^{\circ}$ \\
Cutting speed & 25,35 and $45 \mathrm{~m} / \mathrm{min}$ \\
Feed & $0.06 \mathrm{~mm} / \mathrm{rev}$ \\
Cutting fluid & Water soluble \\
\hline
\end{tabular}

The drilling tests were conducted on a MAHO 700S CNC machining centre and the workpiece was mounted on a Kistler (model 9443B) dynamometer. Water soluble coolant with $6 \%$ concentration was employed throughout the drilling trials. In order to maintain rigidity and stability during the drilling operation, a tool overhang of $35 \mathrm{~mm}$ was employed.

The tools flank wear $\left(\mathrm{Vb}_{2}\right)$ were examined using a Nikon tool-maker's microscope at 30X magnification. The experiment was stopped after drilling a cutting distance of $500 \mathrm{~mm}$ or when any of the following criteria had reached; average non-uniform flank wear $\geq 0.15 \mathrm{~mm}$, maximum flank wear $\geq 0.2 \mathrm{~mm}$, chipping $\geq 0.2 \mathrm{~mm}$ or catastrophic failure. Due to the difference in thickness of the two alloys, there is a discrepancy in the number of hole drilled in determining the tool life criteria. Experiment was stopped after drilling the 25th hole and 32nd hole for Ti-6Al-4V and Ti-5Al-4V-Mo/Fe respectively which is equivalent to $500 \mathrm{~mm}$ cutting length for both materials.

The workpiece surface roughness was measured, using a portable Zeiss HandySurf E-35A across the feed direction. The average values of three readings at different locations were recorded. Samples of the drilled hole (1st and last holes) under various cutting speeds were prepared for the surface integrity analysis (subsurface deformation and micro-hardness). The samples were ground, polished and etched in order to analyse possible metallurgical changes underneath the machined surface using the scanning electron microscope (SEM).

\section{Results and Discussions}

\section{1 Tool wear and tool life}

Non-uniform flank wear and micro-chipping (Fig. 3) were found to dominate the wear pattern under all cutting conditions. These are probably due to the combination of various wear mechanisms such as adhesion, diffusion and plastic deformation which are usually encountered during machining of titanium alloys ${ }^{(1),(2),(4)}$. Adhesion of the workpiece was obviously observed on the chisel edge and the cutting edges at all cutting speeds tested as shown in 


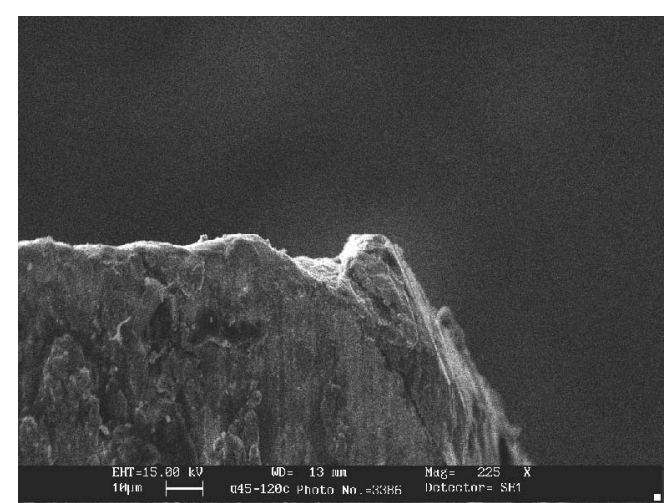

(a) Ti-6Al-4V, at cutting speed of $45 \mathrm{~m} / \mathrm{min}$

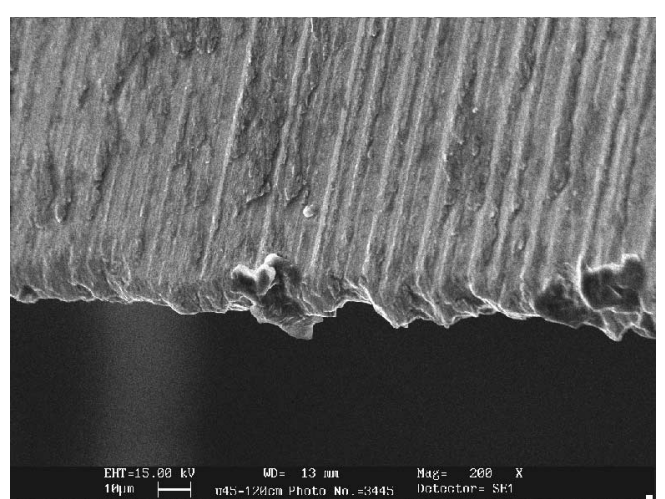

(b) Ti-5 Al-4V-Mo/Fe, at cutting speed of $45 \mathrm{~m} / \mathrm{min}$

Fig. 3 Magnified view showing the evidence of micro-chipping on the cutting edge at the end of tool life

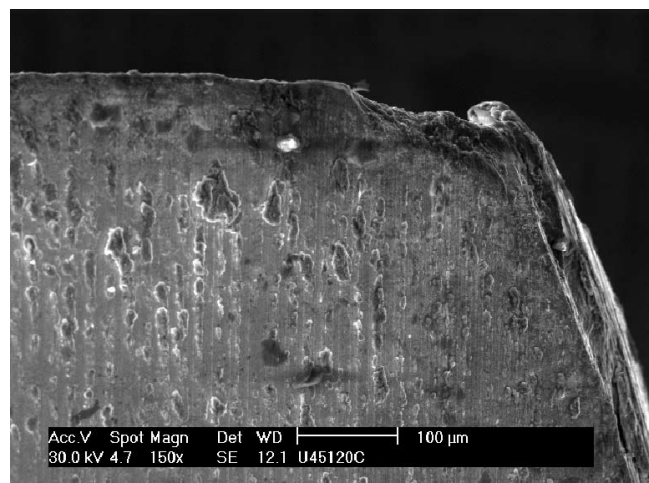

(a)

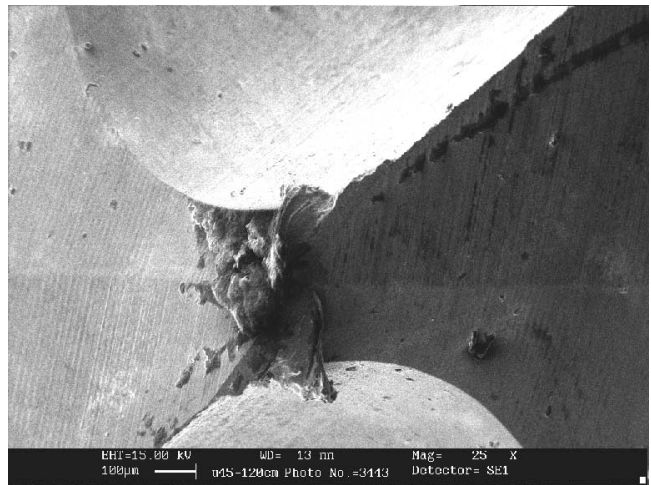

(b)

Fig. 4 SEM images of the flank face and chisel edge showing the adherent of workpiece when drilling (a) Ti-6Al-4V and (b) Ti-5Al-4V-Mo/Fe respectively

Fig. 4. It is dominant when machining at low cutting speed where the size is bigger than at high cutting speed. The strong adhesion of the workpiece to the tool may cause problems in a complex cutting such as drilling. According to Trent ${ }^{(13)}$, with increasing cutting temperature, the adhered layer becomes weaker and can no longer withstand the high compressive stresses, eventually plucking of the tool particles occurred along with the moving chips. This adhesion wear mechanism resulted in severe tool wear and chipping of the cutting edges.

In Fig. 5, it was found that the longest tool life was recorded when machining both Ti-6Al-4V and Ti-5Al-4V$\mathrm{Mo} / \mathrm{Fe}$ at cutting speed of $25 \mathrm{~m} / \mathrm{min}$. Experiment trials for both titanium alloys were stopped when the drilling distance achieved $500 \mathrm{~mm}$ due to the limited source of materials although the wear criteria was still far below the limiting value. Both materials exhibited the same tool life, however Ti-6Al-4V showed a more superior machinability over Ti-5Al-4V-Mo/Fe, perhaps due to the lower wear rate of the tool. Short tool life was recorded at higher cutting speed of $45 \mathrm{~m} / \mathrm{min}$ when drilling both alloys. At higher cutting speed, high cutting temperature was generated due to the low thermal conductivity of titanium alloys, and

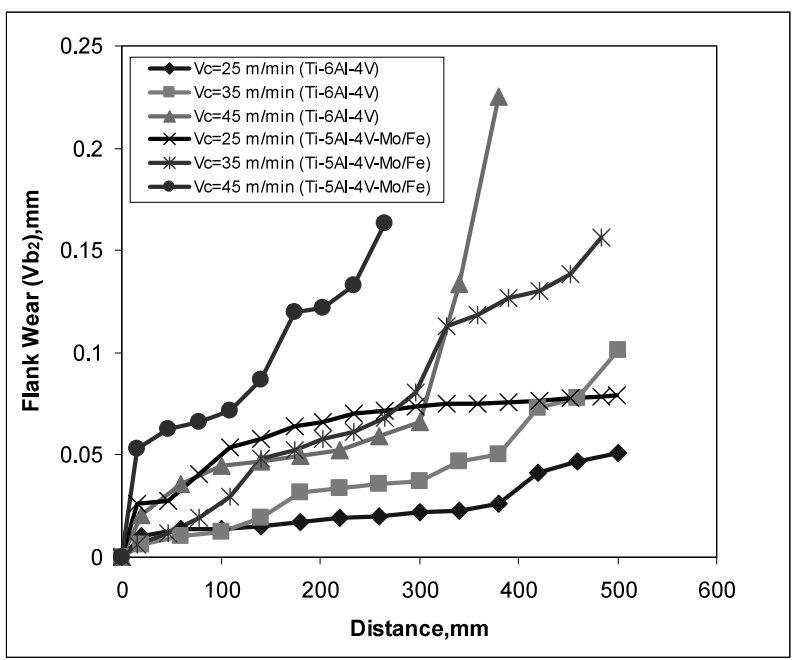

Fig. 5 Tool wear progression

coupled with higher stresses acting at the cutting edges accelerated the tool wear ${ }^{(6),(14)}$, thus resulting in shorter tool life. Overall results showed that Ti-6Al-4V exhibited superior machinability property over Ti-5Al-4V-Mo/Fe alloy at all cutting speeds tested, probably due to the lower tool wear rate and excellent tool life. However this result 


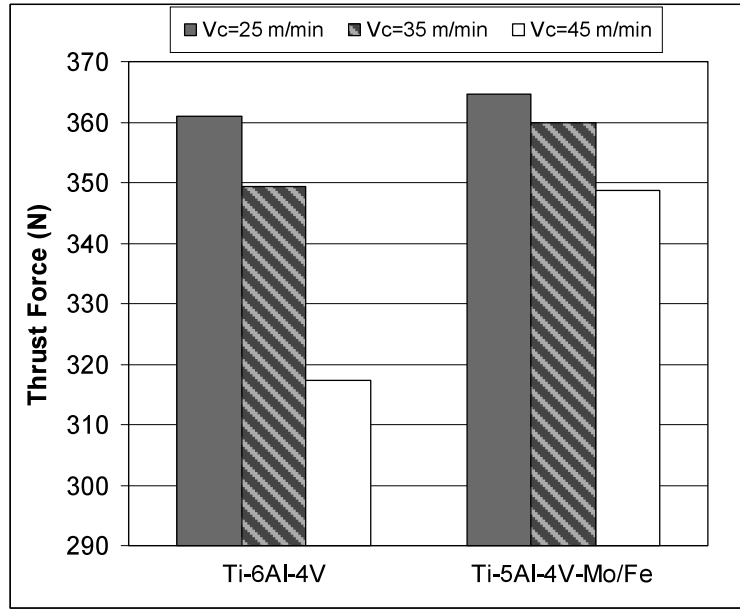

Fig. 6 Effect of cutting speed on thrust force

contradicted the work reported by Kosaka et al. ${ }^{(12)}$, when they found that the low-cost titanium alloy have a better machinability property when compared to Ti-6Al-4V.

\subsection{Thrust force}

The average thrust force for each drilling trial for different type of alloys at different cutting speeds is shown in Fig. 6. The effect of cutting speed on thrust force is quite significant where the thrust force decreases appreciably as the cutting speed increases from of $25 \mathrm{~m} / \mathrm{min}$ to $45 \mathrm{~m} / \mathrm{min}$ for both Ti-6Al-4V and Ti-5Al-4V-Mo/Fe respectively. This phenomenon was due to the effect of high cutting temperature generated at high cutting speed which resulted in lower coefficient of friction. In addition, as the cutting speed increases, the shear angle also increases which resulted in reduction of shear plane area. A decrease in shear plane area decreases the shear force required to produce the stress required for deformation ${ }^{(18)}$. Results also indicate that Ti-6Al-4V produced a lower thrust force when compared with Ti-5Al-4V-Mo/Fe at all cutting speeds tested.

\subsection{Surface integrity}

3.3.1 Surface roughness Figure 7 shows the workpiece surface roughness obtained when drilling Ti$6 \mathrm{Al}-4 \mathrm{~V}$ and Ti-5Al-4V-Mo/Fe with WC-Co tools at various cutting conditions. It was found that the surface roughness values at different cutting speeds varied within the range of 1.18 to $1.75 \mu \mathrm{m}$ and 1.22 to $1.52 \mu \mathrm{m}$ for Ti-6Al-4V and Ti-5Al-4V-Mo/Fe respectively. These results demonstrate that an increase in cutting speeds from $25 \mathrm{~m} / \mathrm{min}$ to $45 \mathrm{~m} / \mathrm{min}$ led to an improvement on the surface roughness values. During the machining at high cutting speed, the cutting temperature increases resulted in a small contact length between tool-workpiece interface and reduced the coefficient of friction ${ }^{(13)}$. The decrease in the surface roughness values may also be attributed to the absence of material side flow on the machined surface at high cutting speeds. It can be suggested that adherence of

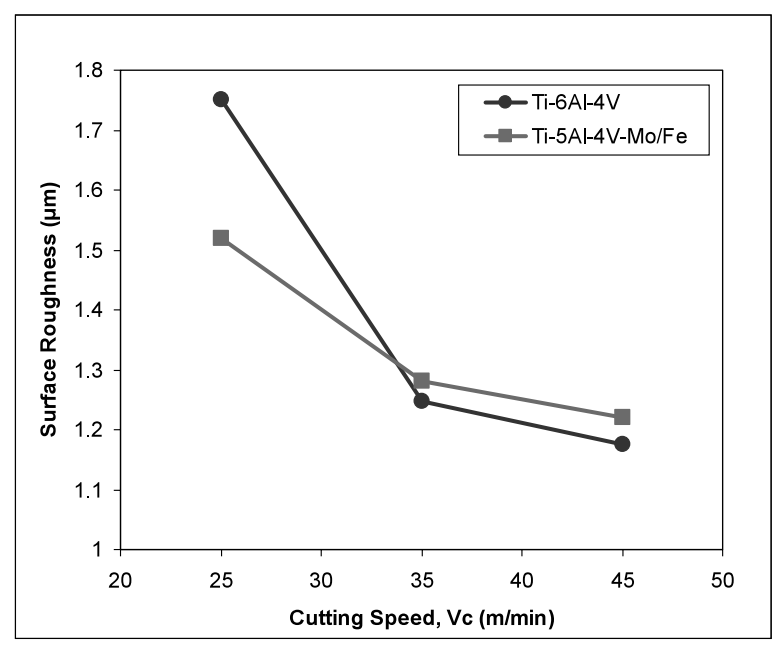

Fig. 7 Workpiece surface roughness of drilled surface at various cutting speeds

the workpiece material at high cutting speed are less pronounce, perhaps due to the high temperature generated.

3.3.2 Metallurgical alteration A visible microstructure alterations were observed on machined surface of Ti-6Al-4V and Ti-5Al-4V-Mo/Fe. Significant microstructure deformation which occurred after prolonged machining as shown in Figs. 8 and 9, due to the localized heating on the machined surface in combination with high stresses generated ${ }^{(15)}$. These figures showed evidence of sub-surface damage on both titanium alloys after prolonged machining where severe plastic deformation of the workpiece material was obvious. However, no white layers were observed on both alloys.

The heat generated at high cutting speed may affect the surface integrity of the workpiece, which is perhaps more important than the tool life ${ }^{(16)}$. At this condition, the high temperature could contribute to the machined surface softening. The combination action of the increased component forces and high temperature at the interface between the tool and the machined surface produce compressive and shear stresses which usually leads to severe plastic deformation ${ }^{(15)}$. The figures also exhibited that the plastic deformation follows the direction of the drill rotation which depends on the cutting conditions employed $^{(17)}$. Prolonged drilling with worn out cutting edges may have resulted in irregular sub-surface which includes surface tearing and severe plastic deformation.

3.3.3 Microhardness Results on the microhardness of the sub-surface layer of the machined surface were presented in Figs. 10 and 11 when drilling Ti-6Al-4V and Ti-5Al-4V-Mo/Fe respectively. It was observed that the microhardness values of the surface layer varied slightly and similar trend was exhibited on both titanium alloys. The hardness value of the surface layer was higher than the average hardness of the workpiece material. It was due to the high cutting temperature generated between tool- 


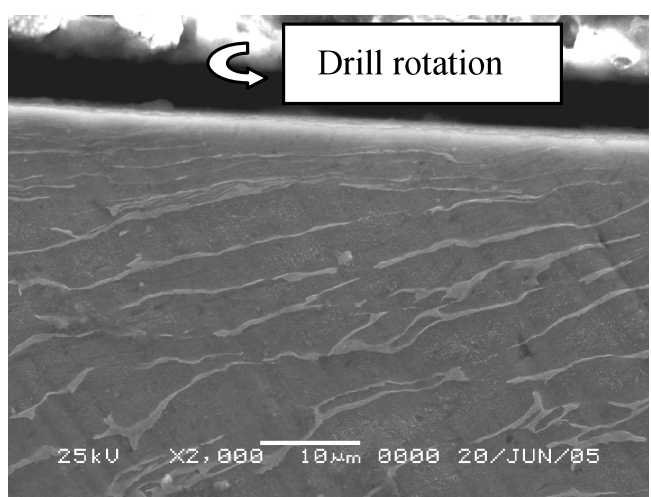

(a) After 7 minutes at $25 \mathrm{~m} / \mathrm{min}$

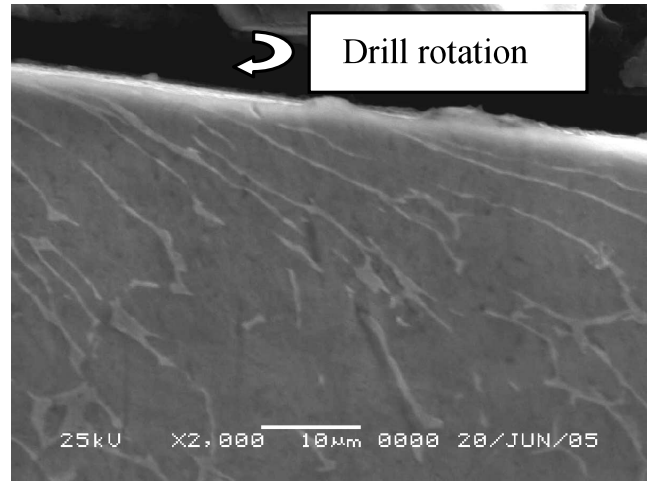

(b) After 3 minutes at $45 \mathrm{~m} / \mathrm{min}$

Fig. 8 Magnified view of the machined sub-surface when drilling Ti-6Al-4V

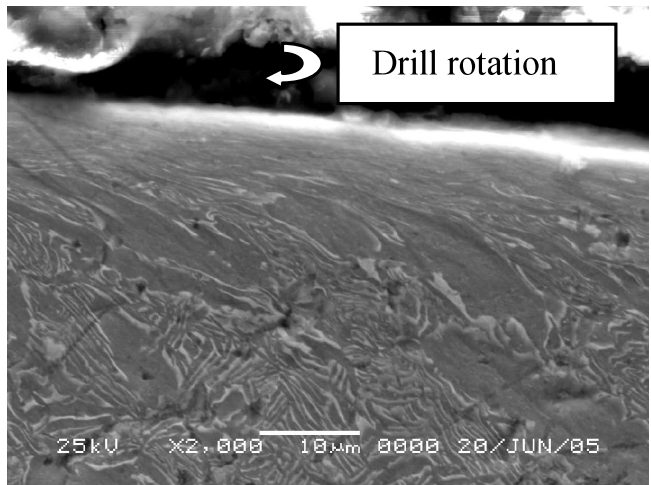

(a) After 7 minutes at $25 \mathrm{~m} / \mathrm{min}$

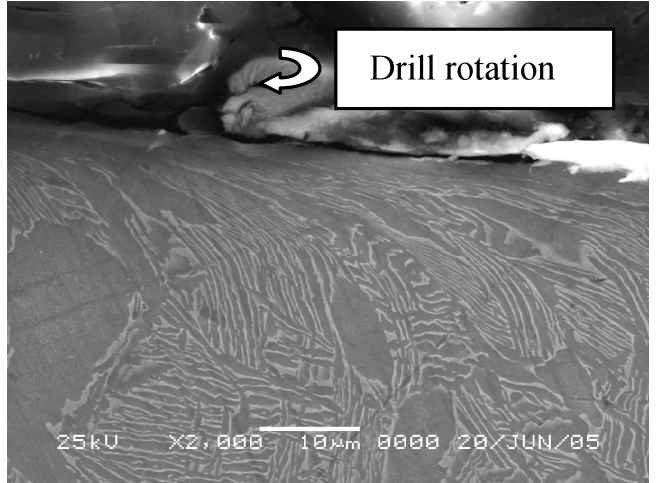

(b) After 2 minutes at $45 \mathrm{~m} / \mathrm{min}$

Fig. 9 Magnified view of the machined sub-surface when drilling Ti-5Al-4V-Mo/Fe

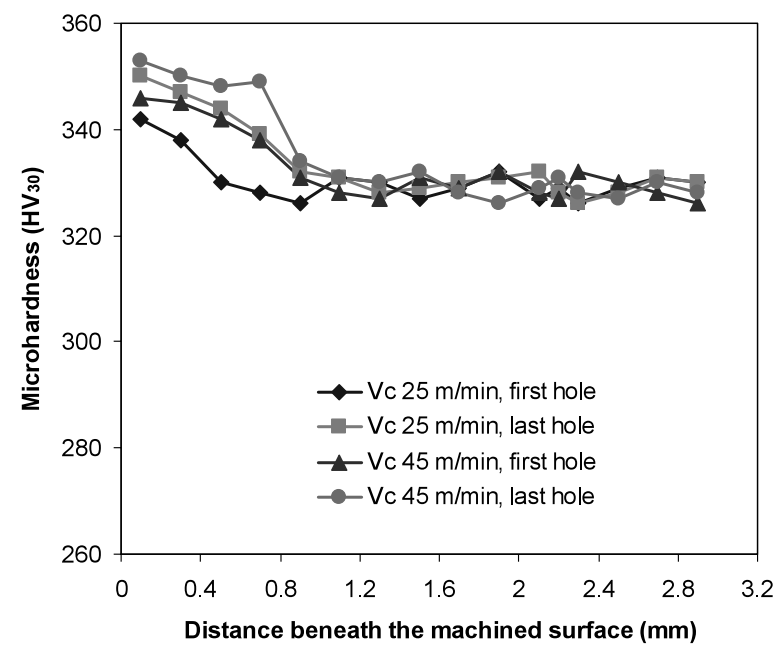

Fig. 10 Microhardness variations beneath the surface produced when drilling Ti-6Al-4V

workpiece interfaces during the drilling process. Similar results were obtained by Ezugwu et al. ${ }^{(15)}$ when turning Inconel 718. According to Che Haron ${ }^{(17)}$, the high hardness value beneath the surface layer was due to the work hardening effect. However, the hardness values tend to decrease towards the average hardness of the workpiece material as the distance beneath the machined surface in-

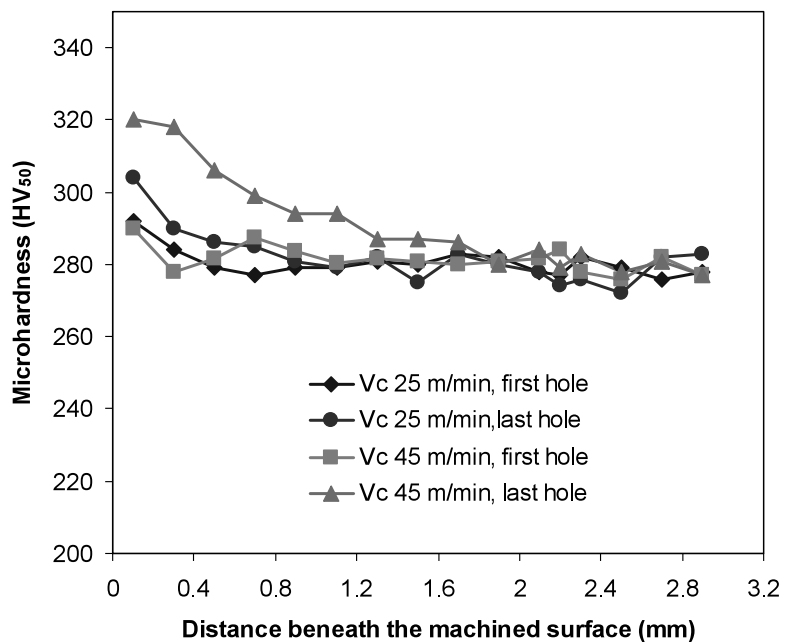

Fig. 11 Microhardness variations beneath the surface produced when drilling Ti-5Al-4V-Mo/Fe

creases.

From Figs. 10 and 11, it can be seen that cutting speed adversely affects the microhardness value of the subsurface layer. At higher cutting speed of $45 \mathrm{~m} / \mathrm{min}$ higher hardness values were obtained when compared with lower cutting speed of $25 \mathrm{~m} / \mathrm{min}$ for both titanium alloys. These results are expected due to the high cutting temperature 
generated when higher cutting speed was employed. Result also showed that the worn tools (last hole) tends to increase the hardness value when compared with sharp tools (first hole). It can be suggested that prolonged machining contributed to a significant increment in hardness value. As the tool becomes worn and dull, rubbing may have occurred instead of the cutting action thus increases the plastic deformation and cold working action which eventually results in an increase of the hardness value of the machined surface ${ }^{(15)}$.

\section{Conclusions}

The effect of cutting speeds on the tool life, tool wear, cutting force and surface integrity of the machined surface during drilling of Ti-6Al-4V and Ti-5Al-4V-Mo/Fe alloys have been investigated experimentally. The following conclusions can be drawn:

(1) Non uniform flank wear and chipping at the cutting edges were the dominant tool failure modes when drilling both titanium alloys at various cutting speeds.

(2) Ti-6Al-4V alloy system exhibited superior machinability property than $\mathrm{Ti}-5 \mathrm{Al}-4 \mathrm{~V}-\mathrm{Mo} / \mathrm{Fe}$ alloy during the drilling operation due to the better tool life performance as a result of lower flank wear rate of the drill.

(3) It was found that the cutting speed has significant effect on the thrust force when drilling Ti-6Al-4V and Ti$5 \mathrm{Al}-4 \mathrm{~V}-\mathrm{Mo} / \mathrm{Fe}$ alloys. Lower thrust force was obtained when drilling Ti-6Al-4V at all cutting speeds tested.

(4) In general the surface roughness of the drilled surface on both alloys, improved with increase in cutting speeds.

( 5 ) Severe plastic deformation of the drilled subsurface was observed on both Ti-6Al-4V and Ti-5Al-4V$\mathrm{Mo} / \mathrm{Fe}$ alloys after prolonged drilling.

(6) Cutting speed and tool wear have a pronounced effect on the metallurgical alteration and microhardness of the machined surfaces of both Ti-6Al-4V and Ti-5Al-4V$\mathrm{Mo} / \mathrm{Fe}$.

\section{Acknowledgements}

The authors would like to express their appreciation to the Research Management Centre (RMC), UTM and the Ministry of Science, Technology and Innovation, Malaysia for their financial support for the above project through the IRPA funding 03-02-06-0086 EA001 - vote no. 74122 .

\section{References}

(1) Konig, W., Applied Research on the Machinability of Titanium and Its Alloys, Proc. 47th Meeting of AGARD Structural and Materials Panel, Florence, (1978), pp.1-10.

( 2 ) Machado, A.R. and Wallbank, J., Machining of Titanium and Its Alloys-A Review, Proc. Instn. Mech.
Engrs., Vol.204 (1990), pp.53-60.

(3) Narutaki, N. and Murakoshi, A., Study on Machining of Titanium Alloys, Annal of the CIRP, Vol.32, No.1 (1983), pp.65-69.

(4) Ezugwu, E.O. and Wang, Z.M., Titanium Alloys and Their Machinability-A Review, Journal of Material Processing Technology, Vol.68 (1997), pp.262-274.

( 5 ) Hartung, P.D. and Kramer, B.M., Tool Wear in Machining Titanium Alloys, Annal of the CIRP, Vol.31, No.1 (1982), pp.75-80.

( 6 ) Jawaid, A., Sharif, S. and Koksal, S., Evaluation of Wear Mechanism of Coated Carbide Tools when Face Milling Titanium Alloy, Journal of Materials Processing Technology, Vol.99 (2000), pp.266-274.

( 7 ) Tonshoff, H.K., Spintig, W. and Konig, W., Machining of Holes Developments in Drilling Technology, Annal of the CIRP, Vol.43, No.2 (1994), pp.551-561.

( 8 ) Sakurai, K., Adichi, K., Ogawa, K. and Niba, R., A Study on Drilling of Ti-6Al-4V by Tin Coated Drills, Int. Conf. on Recent Advances in Science and Engineering of Light Metals, (1991), pp.803-808.

( 9 ) Arai, M. and Ogawa, M., Effects of High Pressure Supply of Coolant in Drilling of Titanium Alloy, Journal of Japan Institute of Light Metals, Vol.47, No.3 (1997), pp.139-144.

(10) Fujise, K. and Ohtani, T., Machinability of Ti-6Al-4V Alloy in Drilling with Small Drills, Proc. of the Fourth Int. Conf. on Progress of Cutting and Grinding, Urmqi and Torpan, China, (1998), pp.49-54.

(11) Sharif, S. and Rahim, E.A., The Effect of Coatings on Performance of Carbide Tools when Drilling Titanium Alloy Ti-6Al-4V, Proceedings of the 8th CIRP International Workshop on Modeling of Machining Operations, Chemnitz, Saxony, Germany, (2005), pp.577582.

(12) Kosaka, Y., Fanning, J.C. and Fox, S.P., Development of Low Cost High Strength Alpha/Beta Titanium Alloy with Superior Machinability, 10th World Conf. on Titanium Ti-2003, Hamburg, Germany, (2003), pp.102108.

(13) Trent, E.M., Metal Cutting, 3rd Edition, (1991), Butterworth-Heinemann Ltd., London.

(14) Zlatin, N. and Field, M., Procedures and Precautions in Machining Titanium Alloys, 2nd Int. Conf. on Titanium, Cambridge, Massachusetts, (1972), pp.489-504.

(15) Ezugwu, E.O., Wang, Z.M. and Okeke, C.I., Tool Life and Surface Integrity when Machining Inconel 718 with PVD and CVD Coated Tools, Tribology Transaction, Vol.42 (1999), pp.353-360.

(16) Li, L., Chang, H., Wang, M., Zuo, D.W. and He, L., Temperature Measurement in High Speed Milling Ti-6Al-4V, Key Engineering Materials, Vol.259-260 (2004), pp.804-808.

(17) Che Haron, C.H., Tool Life and Surface Integrity in Turning Titanium Alloy, Journal of Materials Processing Technology, Vol.118 (2001), pp.231-237.

(18) Liu, G., He, N., Man, Z.L. and Li, L., Cutting Force in the Milling of Inconel 718, Key Engineering Material, Vol.259-260 (2004), pp.824-828. 